\title{
PARTICIPAÇÃO DO ASSISTENTE SOCIAL EM INSTÂNCIAS DE CONTROLE SOCIAL DEMOCRÁTICO: LIMITES E DESAFIOS
}

Andréa Márcia Santiago Lohmeyer Fuchs, Breno Jaime Amaral Souto, Gabriela Isabel de Jesus.

Universidade Federal de Santa Catarina - UFSC, Departamento de Serviço Social, Florianópolis, SC. E-mail: andrea.fuchs@ufsc.br

\section{RESUMO}

A Constituição Federal de 1988 foi o marco inicial para a participação social descentralizada. A referente pesquisa trata de como estão sendo executadas as medidas socioeducativas de liberdade assistida e prestação de serviços à comunidade pelos assistentes sociais na mesorregião da Grande Florianópolis. A metodologia adotada foi a abordagem qualitativa com formulário online aplicado em 22 municípios e nove entrevistas com visita in loco com assistentes sociais. Parte da metodologia traçou o perfil profissional e inclusive a participação em espaços políticos de controle democrático. 0 objetivo deste presente estudo ressalta os desafios dessa participação encontrados no cotidiano profissional. Os dados sugerem que a participação do assistente social nesses espaços ainda é deficitária, muito embora esteja presente enquanto orientação do projeto ético-político da categoria. Para tanto, o profissional precisa ter clareza da importância da sua participação para o fortalecimento das deliberações nas políticas públicas.

Palavras-chave: Controle Democrático, Participação social, Projeto ético-político, Serviço Social.

\section{PARTICIPATION OF THE SOCIAL WORKER IN INSTANCES OF SOCIAL DEMOCRATIC CONTROL: limits and} challenges.

\begin{abstract}
The Federal Constitution of 1988 was the starting point for decentralized social participation. The research refers to how the socioeducative measures of assisted freedom and community service delivery by the social workers in the Greater Florianópolis mesoregion are being carried out. The methodology adopted was the qualitative approach with an online form, interviews in 22 municipalities and an on-site visit. Part of the methodology traced the professional profile and even the participation in political spaces of democratic control. The objective of this present study emphasizes the challenges of this participation found in professional daily life. The data suggest that the participation of the social worker in these spaces is still deficient, even though it is present as a guideline of the category's ethical-political project. For this, the professional needs to be clear about the importance of his participation in order to strengthen the deliberations on public policies.
\end{abstract}

Keywords: Democratic Control, Social participation, Ethical-political project, Social service.

\section{INTRODUÇÃO}

A Constituição Federal de 1988 (CF/88) trouxe diretrizes baseadas na descentralização político-administrativa e participação. Tais diretrizes além da reconfiguração nas relações entre as esferas governamentais, com ênfase na municipalização dos serviços a serem prestados, incorporou a sociedade civil no âmbito da esfera pública estendendo, para além das atribuições de execução historicamente realizadas, sua atuação nos processos de formulação, deliberação e fiscalização. Atuação essa em um extenso leque de políticas e programas, como as políticas setoriais de saúde e educação, as políticas transversais de direitos humanos, reconfigurando a estrutura organizativa do Estado brasileiro. A participação nos processos decisórios da agenda pública das políticas foi materializada nos espaços de controle social democrático, entre eles os Conselhos gestores das políticas públicas sociais (conhecidos também como Conselhos de 
Direitos) e as Conferências nas três esferas governamentais (nacional, estadual e municipal).

O Serviço Social enquanto profissão historicamente determinada pela emergência das desigualdades sociais e suas consequências na vida da classe trabalhadora sempre foi chamado para atuar nos diferentes espaços sócioocupacionais. A defesa intransigente pela ampliação de direitos, justiça social e equidade foram demandando cada vez mais a participação de assistentes sociais nos espaços políticoinstitucionais de decisão das políticas públicas sociais. Assim, a participação do assistente social, norteada pelo projeto ético-político da profissão, contribui para qualificar as funções nestes espaços, seja como assessoria, acompanhamento e capacitação. Para lamamoto (2004, p. 21), “o assistente social inicia um novo processo no que se refere à profissão, uma vez que este profissional passa a participar não somente da execução, mas também da formulação e gestão das políticas públicas". Sendo que, a participação do assistente social nos espaços públicos de controle social e participação política junto à sociedade é considerado um ganho significativo no que tange a garantia de direitos.

A referente pesquisa objetivava analisar como o assistente social tem desenvolvido sua prática interventiva nos programas/serviços de medidas socioeducativas em meio aberto de Liberdade Assistida - LA e Prestação de Serviços à Comunidade - PSC. Entretanto, foi feito um recorte na importância e desafios encontrados por esse profissional na participação nos espaços de controle social, que também é abordado quando é traçado o perfil do profissional.

\section{METODOLOGIA E PROCEDIMENTOS DE INVESTIGAÇÃO}

A análise preliminar desta pesquisa adotou como base de estudos a pesquisa qualitativa que, segundo Minayo (2007) trabalha com o universo de significados, motivos, aspirações, crenças, valores e atitudes, o que corresponde a um espaço mais profundo das relações, dos processos e dos fenômenos que não podem ser reduzidos à operacionalização de variáveis.

O cenário de estudo definido foi a mesorregião Grande Florianópolis, dividida segundo a Federação Catarinense dos Municípios
(FECAM) ${ }^{1}$, composta por 22 municípios da Grande Florianópolis.

A pesquisa conta em sua metodologia geral aplicação de questionário online com 22 assistentes sociais, entrevista semiestruturada com nove as/os assistentes sociais dos serviços/programas, visita técnica institucional aos locais de execução do serviço de medida socioeducativa (de LA e PSC), observação livre in loco, por ocasião da realização das entrevistas e análise de documentos institucionais. Por se tratar de uma análise preliminar de dados na primeira etapa de coleta de dados da pesquisa, foram utilizados apenas os dados referentes ao questionário online, onde foi levantado e sistematizado o perfil do Assistente social através da ferramenta Google Formulário.

Por se tratar de uma pesquisa que envolve seres humanos, no que diz respeito aos preceitos éticos, a pesquisa foi submetida, apreciada e aprovada sob CAAE: 72877017.2.0000.0121 pelo Comitê de Ética em Pesquisa de Seres Humanos da Universidade Federal de Santa Catarina - CEPSH/UFSC.

\section{RESULTADOS}

A pesquisa contou com 21 respondentes do total de municípios pesquisados (22). Desse total 10 assistentes sociais fazem parte de municípios de Pequeno Porte ${ }^{2} \mathrm{I}$, sendo majoritariamente do sexo feminino (95\%). 76,2\% dos assistentes sociais declararam ter religião e deste $47,6 \%$ se diziam católicos. Em relação à pertença étnico-racial $86 \%$ se autodeclaram brancos seguidas de $9 \%$ negros (Tabela 1 ).

\footnotetext{
${ }^{1}$ A FECAM possui trajetória de mais de 30 anos à frente do Movimento Municipalista em Santa Catarina, tem parceria com 21 associações de municípios de todo o estado.

${ }^{2} \mathrm{PPI}$ - Pequeno Porte I (até 20 mil habitantes); PPII - Pequeno Porte II (de 20 mil à 50 mil habitantes); MP - Médio Porte (de 50 mil à 100 mil habitantes); GP - Grande Porte (de $100 \mathrm{mil}$ à $900 \mathrm{mil}$ habitantes).
} 
Tabela 1. Municípios segundo porte, sexo e raça/cor dos profissionais

\begin{tabular}{llllll}
\hline Porte dos & & & Raça/cor & \\
\cline { 3 - 6 } Municípios & Sexo & Total & Brancos & Negros & Outros \\
\hline Grande Porte & Feminino & 6 & 5 & 0 & 1 \\
Pequeno Porte I & Feminino & 9 & 8 & 1 & 0 \\
& Masculino & 1 & 0 & 1 & 0 \\
Porte Pequeno II & Feminino & 4 & 4 & 0 & 0 \\
Médio Porte & Feminino & 1 & 1 & 0 & 0 \\
\hline Total Geral & & 21 & 18 & 2 & 1 \\
\hline
\end{tabular}

Fonte: Elaboração Própria (2018)

No que diz respeito à formação acadêmica $67 \%$ tiveram formação em Universidade Pública e $28 \%$ em universidades particulares.

Sobre participação nos espaços de controle social democrático, $62 \%$ dos assistentes sociais declararam não participar de nenhum processo de articulação política fora o espaço sócio-ocupacional na qual trabalha. Do total daqueles que participam (38\%) a maioria está nos municípios de PPI, especialmente nos Conselhos Municipais de Assistência Social e Conselhos de Direitos da Criança e do Adolescente. Nos demais apenas no município de Grande porte um assistente social participa no Conselho profissional da sua categoria (Conselho Regional Serviço Social - CRESS).

\section{DISCUSSÃO}

O termo público associado à política é uma referência "à coisa pública" (res publica), que, portanto, afeta a todos, sob a égide de uma lei e o apoio de uma comunidade de interesses, não sendo uma referência exclusiva do Estado. As políticas públicas e sociais ao comporem a ossatura material do Estado, não podem ser compreendidas somente como interesse de uma classe. As políticas públicas, entre elas as sociais, englobam preferências, escolhas e decisões privadas, devendo, por isso, serem controladas pelos cidadãos (PEREIRA, 2008).

A configuração da política de atenção aos direitos da criança e adolescente, desenhada a partir dos Conselhos de Direitos (Federal, Estadual e Municipal), trazida pela CF/88 e em especial a partir do Estatuto da Criança e do Adolescente (ECA), Lei n. 8.069/1990, tem afetado diretamente a política de atendimento aos adolescentes autores de ato infracional, seus equipamentos e serviços. É no âmbito desse Conselho que se dá a construção da política e planos de ação local de maneira democrática e de interesse público, possibilitando diálogos e defesas dos projetos societários que se encontram na cena pública (PEREIRA, 2008).

Por sua vez o assistente social é um profissional historicamente requisitado para atuar no enfrentamento das questões sociais, por meio dos diferentes espaços sócio-ocupacionais, entre eles os programas que executam as medidas socioeducativas. Ao pautar suas práticas profissionais a partir dos princípios definidos no projeto ético-político profissional, entende-se que a participação do assistente social nos espaços dos Conselhos de Direitos, em especial nos municipais, são estratégicos na luta e garantia dos direitos das crianças e adolescentes, incluindo aqueles que cometeram atos infracionais.

Contudo, a referida pesquisa, sugere que a participação do assistente social está deficitária, pois a maioria dos assistentes sociais pesquisados apontam a não participação em nenhum espaço de articulação política. Maia (2002) sinaliza que um dos importantes campos e/ou área de atuação dos assistentes sociais tem sido os direitos e políticas sociais, por meio inclusive de sua inserção nos Conselhos gestores de políticas públicas, ou os conselhos de direitos. A autora complementa dizendo que esse entendimento é resultado do processo avaliativo e organizativo da categoria, construído ao longo dos últimos anos no Brasil e que está explicitado na Lei de Regulamentação da Profissão (Lei n. 8.662/1993) e no Código de Ética Profissional (Resolução n. 273/1993), que se constituem em baluarte desses trabalhadores inseridos na divisão social e técnica do trabalho.

A contribuição do assistente social nesses espaços, segundo Simionatto (1999, p.19), "se dá entre outros no nível político, pois os conhecimentos em relação aos direitos, democracia e cidadania permitem a efetiva participação no processo político organizativo" E para o tal o assistente social deve ter uma prática pautada no projeto ético-político da profissão. 
Nos princípios do Código de Ética Profissional, o assistente social deve contribuir para a "ampliação e consolidação da cidadania [...] com vistas à garantia dos direitos civis, sociais e políticos das classes trabalhadoras", bem como defesa da democracia "enquanto socialização da participação política" e "compromisso com a qualidade dos serviços prestados à população e como o aprimoramento intelectual, na perspectiva da competência profissional" (CONSELHO FEDERAL DE SERVIÇO SOCIAL, 1993, p. 23).

No Brasil, historicamente percebe-se dificuldades quanto à participação dos cidadãos. Muitos reclamam do autoritarismo dos governos, a não transparência das ações e ainda, que participação não gera resultados neste país. É preciso pensar a democracia participativa, compreendendo também as especificidades da cultura política local/regional/nacional.

\section{CONCLUSÃO}

A partir de 1988 tivemos uma expansão quantitativa dos conselhos gestores, ou de direitos, e mesmo o seu caráter deliberativo não significou necessariamente seu sucesso em superar os desafios a eles impostos (GOMES, 2000). Muito embora sua existência possibilite maior vigilância social sobre o Poder Executivo, algumas questões precisam ser avaliadas quando tratamos de criação e implementação de conselhos gestores, tais como: a representatividade qualitativa dos segmentos sociais, o quantitativo referente à paridade (governo e sociedade civil), capacitação, acesso à informação, entre outros (GOHN, 2001).

Ao atuar sobretudo na execução terminal das políticas sociais, tendo como fundamento de suas práticas o projeto ético-político, a participação de assistentes sociais nos espaços de controle social, como os conselhos de direitos, pode contribuir no enriquecimento acerca do conhecimento das referidas políticas públicas e seu funcionamento e na luta pelo fortalecimento e ampliação dos direitos de crianças e adolescentes no Brasil.

\section{REFERÊNCIAS}

BRASIL. Constituição (1988). Constituição da

República Federativa do Brasil. Brasília, DF: Senado Federal, 1988.
BRASIL. Câmera dos Deputados. Estatuto da Criança e do Adolescente. Lei № 8.069, de 13 de julho de 1990. Brasília, 1990.

CONSELHO FEDERAL DE SERVIÇO SOCIAL. Código de Ética Profissional do assistente social. Brasília, CFESS, 1993.

GOHN, M. G. Conselhos Gestores e participação sociopolítica. São Paulo: Cortez, 2001. v. 84 (Coleção questões da nossa época).

GOMES, A. L. Novos espaços ocupacionais do assistente social: Os Conselhos de políticas e de direitos. In: Capacitação em Serviço Social e Política Social. Brasília, CEAD - Unb, 2000. Módulo 4.

IAMAMOTO, M. V. O serviço social na contemporaneidade: trabalho e formação profissional.São Paulo: Cortez, 2004.

MAIA, M. Fórum dos Conselhos Estaduais de Políticas e Direitos Sociais - o serviço social no processo de articulação. Revista Virtual Textos e Contextos, Porto Alegre, n1, ano I, nov. 2002.

MINAYO, M. C. de S. O desafio do conhecimento. 10. ed. São Paulo: HUCITEC, 2007.

PEREIRA, P. A. P. Discussões conceituais sobre política social como política pública e direito de cidadania. In: BOSCHETTI, I. et al. (org.). Política social no capitalismo: tendências contemporâneas. São Paulo: Cortez, 2008.

SIMIONATTO, I. Caminhos e descaminhos da política de saúde no Brasil. Revista Inscrita/ Dossiê CFESS, 1999.

Recebido para publicação em 20/05/2018

Revisado em 15/08/2018

Aceito em 24/08/2018 